\title{
Função fraterna: reflexões a partir do filme Príncipe das Marés
}

Fraternal function: reflections based on the movie The prince of tides

Función fraterna: reflexiones a partir de la película Príncipe de las marés

\author{
Aline Amaral Mussumeci Muniz* \\ Terezinha Féres-Carneiro ${ }^{* *}$
}

\begin{abstract}
Resumo
Somente a partir do século XXI surge um interesse maior pelo estudo da fratria na área da Psicologia. Neste trabalho, propõe-se desenvolver um estudo teórico na perspectiva psicanalítica, buscando analisar a importância da relação fraterna na estruturação do psiquismo do sujeito e a relevância da presença do irmão no compartilhamento de uma história comum ao longo da vida. São utilizados os conceitos de autores clássicos, como Freud e Lacan, e ainda de outros teóricos contemporâneos, como Kaës, Kancyper e Kehl. Para complementar a discussão, analisa-se a relação entre os irmãos, retratada no filme intitulado "Príncipe das marés", no qual um irmão-gêmeo é convidado a ajudar no tratamento do quadro depressivo da sua irmã, a partir do resgate de sua memória e história de vida.
\end{abstract}

Palavras-chave: Fratria, Função fraterna, Irmão, Memória compartilhada.

\begin{abstract}
It is only in the $21^{\text {st }}$ century that emerges the interest in studying brotherhood in the field of Psychology. The goal of the present work is to develop a theoretical study, from a psychoanalytic perspective, analyzing the importance of fraternal relationships in the structuring of subjects' psyche and the relevance of siblings' presence in sharing common stories throughout life. We adopt concepts from classical authors, such as Freud and Lacan, as well as other contemporary authors such as Kaës, Kancyper e Kehl. In order to complement the discussion, we analyze the siblings' relationship portrayed in the movie "The Prince of Tides", in which a man is requested to participate in the treatment of her depressive twin
\end{abstract}

Psicóloga e terapeuta de família e casal pela PUC Rio.

** Professora titular e coordenadora do Curso de Especialização em Terapia de Família e Casal do Departamento de Psicologia da PUC Rio. E-mail: teferca@puc-rio.br. 
sister, rescuing her memory and life history.

Keywords: Brotherhood, Fraternal role, Siblings, Shared memory.

Resumen

Solamente a partir del siglo XXI surge un interés mayor por el estudio de la fratria en la área de la Psicología. En este trabajo, se propone desarollar un estudio teórico en la perspectiva psicoanalítica, buscando analisar la importancia de la relación fraterna en la estructuración del psiquismo del sujeto y la relevancia de la presencia del hermano en el compartimiento de una historia común, al largo de la vida. Son utilizados los conceptos de autores clásicos como Freud y Lacan y aún otros autores contemporâneos, como Kaës, Kancyper e Kehl. Para complementar la discusión, se analisa la relación entre los hermanos, retratada en la película intitulada "Príncipe das Marés", en la cual uno de los hermanos gemelos es invitado a ayudar en el tratamiento del cuadro depresivo de su hermana, a partir del rescate de su memoria e historia de vida.

Palabras claves: Fratria, Función fraterna, Hermano, Memoria compartida.

\section{A}

$s$ funçôes materna e paterna e as relações pais e filhos têm sido muito estudadas, mas poucos são os estudos acerca da importância da função fraterna para o sujeito. Com exceção de alguns autores clássicos, como Freud e Lacan, somente a partir do século XXI, outros teóricos se interessaram pelo tema da relação entre irmãos (Kaës, 1999; Kancyper, 1999; Kehl, 2000).

A relação entre os irmãos se constitui com base em uma grande intimidade que não é escolhida, mas imposta pelos pais. Desde cedo, os filhos sabem que os pais lhes concederam aqueles parceiros para a vida. $\mathrm{Na}$ hierarquia familiar, os irmãos fazem parte do mesmo subsistema ao longo da vida, sendo assim, são coparticipantes de uma relação igualitária, duradoura e complexa. A fratria permite uma vasta e complexa rede de vivências que só podem ser compartilhadas entre os irmãos. Com base na identificação das diferenças e semelhanças entre eles, cada um poderá se perceber como sujeito.

Ao longo da vida, o irmão exerce grande influência na forma como o sujeito vai se vincular aos outros, pois o irmão é, às vezes, a representação de um primeiro outro, que permite ao sujeito se reconhecer e se socializar. Nesse sentido, pode-se reconhecer que a relação fraterna desempenha um papel 
importante na história de cada irmão/pessoa no decorrer do ciclo de vida.

Considerando o entendimento de que o irmão é a representação de um outro de que o sujeito necessita para se constituir, acredita-se ser de grande relevância o estudo das repercussóes da relação fraterna na constituição do sujeito. Neste trabalho, propõe-se desenvolver um estudo teórico na perspectiva psicanalítica, buscando analisar a importância da relação fraterna na estruturação do psiquismo do sujeito e a relevância da presença do irmão no compartilhamento de uma história comum ao longo da vida.

É importante destacar que a função fraterna não se limita apenas a uma relação entre irmãos biológicos. Os irmãos podem ser ligados por laços afetivos, como ocorre nas famílias reconstituídas, em que há padrastos e madrastas com filhos. Os filhos únicos também podem ter relações com amigos ou primos que funcionem intersubjetivamente como vínculos fraternos, permitindo, assim, a existência de uma função fraterna. Ou mesmo pais, tios, avós, que, de alguma forma, estabeleçam uma relação de horizontalidade, numa situação de paridade, como jogar uma partida de futebol, podem desempenhar a função fraterna. Assim, podemos considerar, de forma mais ampla, que a fratria pode ser representada por outros vínculos que não somente aqueles com os irmãos biológicos.

Neste trabalho, na discussão sobre a função fraterna, são utilizados conceitos de autores clássicos, como Freud e Lacan, e ainda de outros teóricos contemporâneos. Posteriormente, para complementar a discussão teórica, analisa-se a relação entre os irmãos retratada no filme intitulado "Príncipe das marés", ${ }^{1}$ no qual um irmão gêmeo é convidado a ajudar no tratamento do quadro depressivo da sua irmã, com base no resgate de sua memória e história de vida.

\section{O que alguns autores têm a nos dizer sobre a função fraterna}

Freud (1913/1969) introduz a ideia de complexo fraterno, mas sem grande aprofundamento. A relevância dada, pela Psicanálise, ao complexo edípico na estruturação da personalidade e do desejo ocultou o valor específico do complexo fraterno. No entanto, Freud (1921/1969) admitiu, no final de sua vida, a importância do complexo fraterno, embora não o tenha fundamentado de modo sistemático, como o fez com o complexo de Édipo.

Em "Totem e tabu" (1913/1969), o autor aborda o laço fraterno, com

Título original: "The Prince of Tides", filme americano, de 1991, da categoria de drama, dirigido por Bárbara Streisand, e no elenco Bárbara Streisand, Nick Nolte e Jason Gould, com duração de 132 minutos. 
base no mito da existência de uma horda primitiva que teria dado origem à civilização humana. A horda primitiva seria regida por um pai tirânico, todo-poderoso, com autonomia sobre a vida e a morte de seus membros. $\mathrm{O}$ pai tirânico teria muitas regalias, entre elas o poder de desfrutar sexualmente das mulheres do clâ, consideradas suas esposas, independente da ordem de descendência.

Assim, esse pai teria o domínio sobre os filhos no exercício sexual e a desobediência a essa condição representaria ato de rebeldia ao poder paterno. Os filhos eram imediatamente mortos pelo próprio pai, como consequência da desobediência à sua soberania sexual.

Numa posição de submissão e fragilidade, diante de um pai tirânico e forte, os filhos subjugar-se-iam, pelo medo da morte, ao poder do soberano. Entretanto, numa ocasião, os filhos decidiram desafiar a figura onipotente do pai, única forma de encontrarem a libertação da tirania. Acreditaram que, juntos, teriam uma força maior que a do pai, o que não tinham na condição individual. Assim, uniram-se e o mataram de forma impiedosa.

Após a morte do pai, decorrido um lapso de tempo de disputas em que lutavam pela herança paterna que cada um queria só para si, os irmãos perceberam que nenhum deles poderia ocupar o lugar do tirano, pois poderia causar a mesma inveja e o mesmo ciúme que o pai havia despertado neles. A percepção do perigo e a inutilidade da luta, somados à culpa e ao arrependimento pelo parricídio os levaram a unir-se e instaurar uma associação de irmãos com o tabu do incesto e a exogamia. É importante destacar que essa associação de irmãos com regras próprias funcionou como meio de evitar a violência, a intolerância das diferenças e até mesmo a segregação dos irmãos, assegurando, assim, a força e a unidade do grupo.

Houve, então, um deslocamento dos investimentos narcísicos, dirigidos à figura do pai, para a figura do irmão e para os valores da cultura. A ênfase é dada ao conflito edípico com a proibição do parricídio, do incesto e o posterior laço social. O elo do grupo fraternal será um acordo que sobreviverá à falta e tolerará a diferença, apesar das ameaças provocadas pela competição, hostilidade e rivalidade.

Freud (1917/1969), em alguns relatos de casos clínicos, sugere que o irmão se apresenta como o intruso, aquele que disputará o amor dos pais, que anteriormente seria exclusivo. Os ciúmes, advindos do nascimento de um novo irmão, eram considerados como sendo derivados do sentimento de rivalidade reprimido em relação ao amor dos pais. 
No pequeno Hans, Freud (pode acompanhar o sofrimento e a aversão do menino pela irmã, que nasce quando ele tinha 3 anos e meio. "A afeição por sua irmã podia vir mais tarde, mas sua primeira atitude foi de hostilidade. Dessa época em diante, o medo de que ainda pudesse chegar outro bebê encontrou lugar em seus pensamentos conscientes" (Freud, 1909/1969, p. 105). O menino Hans percebeu que a chegada da irmã representava a perda da atenção exclusiva e cuidado parental e temia o nascimento de novos irmãos. Em "História de uma neurose infantil", Freud (1917/1969) ainda registrou a manifestação de um sentimento hostil do menino em relação à sua irmã mais velha, a ponto de este se distanciar da irmã.

Lacan (1987) nomeia complexo de intrusão a experiência que o sujeito primitivo realiza quando se percebe em relação com seus semelhantes, ou seja, quando se reconhece como tendo irmãos. O irmão se apresenta, para o infante, como pequeno sujeito humano, como um duplo que vem desestabilizar a identidade imaginária da criança em relação à sua imagem no espelho.

A entrada de um pequeno semelhante no campo narcísico da criança pode fazer com que ela confunda a si mesmo com o outro. Para a criança, a imagem do outro está ligada à estrutura de seu próprio corpo. Entretanto, a partir da percepção da imagem unificada do corpo do outro, o infante identifica a reunificação do seu próprio corpo, até então supostamente percebido como despedaçado.

Assim, no "Estágio do Espelho", Lacan (1987) pontua a função do outro como essencial para que a criança se mova do encantamento alienante em relação à própria imagem para uma objetivação do eu, com base no processo de identificação. O autor considera o ciúme infantil, em sua essência, como uma identificação mental no complexo de intrusão e não simplesmente um sentimento de rivalidade em torno do amor dos pais. Ele afirma que a estrutura do ciúme infantil permite ao infante se reconhecer como sujeito e como ser social.

Kaës (1999) ressalta que Lacan aborda "o drama do ciúme" como formador da constituição correlativa do eu e do semelhante. O drama permite a percepção de um terceiro objeto que substitui a confusão afetiva e a ambiguidade especular pela concorrência de uma situação triangular.

O autor considera o complexo fraterno como uma organização fundamental dos desejos amorosos, narcísicos e objetais, do ódio e da agressividade perante a esse outro que o sujeito identifica como irmão ou irmã. Esse complexo se instaura na estrutura das relações intersubjetivas, 
organizadas pela representação inconsciente, dos lugares correlativos que ocupam o sujeito, o irmão e a irmã em relação ao objeto do desejo da mãe e ou do pai.

Para Benghozi e Carneiro (2001), a fratria é uma entidade psíquica grupal sincrônica, diferente da soma dos psiquismos individuais dos irmãos e das irmãs, ou seja, há um aparelho psíquico específico do grupo fratria, um continente fratria. A fratria seria um organizador do laço genealógico. O grupo de irmãos e irmãs partilha entre si a herança do patrimônio psíquico familiar transmitido de geração em geração. Segundo os autores, a transmissão de tal patrimônio pode-se dar de modo transgeracional, ou seja, quando a herança psíquica recebida das gerações anteriores não é metabolizada e transformada, ou de modo intergeracional, quando os sujeitos, por uma postura criativa, podem metabolizar e transformar o material psíquico que foi herdado das gerações anteriores.

Esses autores ainda fazem uma distinção entre laço fraterno e relação fraterna. O laço fraterno seria o partilhar do mesmo laço de filiação, ou seja, ser irmão e irmã em uma mesma família; já a relação fraterna explicitaria a qualidade dessa relação, que poderá ser próxima ou distante, fria ou calorosa, amistosa ou conflituosa.

Em "Irmãos: como entender essa relação", Rufo (2003) enfatiza a importância da companhia de um irmão na construção da personalidade. Ressalta que cada um dos membros da fratria, para existir no grupo, deve encontrar seu "nicho", a fim de diferenciar-se dos outros. A diferenciação é indispensável para haver equilíbrio psíquico.

Kancyper define o irmão como um semelhante demasiado similar, a primeira aparição do estranho na infância. O irmão seria um outro, diferente e complementar simultaneamente, que funciona como fundador do eu e constitutivo da alteridade. "E por meio dos vínculos fraternos, o sujeito instala-se - mediante sentimentos de pertinência - nos efeitos estruturantes-desestruturantes que provêm da realidade social" (Kancyper, 1999, p. 75).

Assim, em consonância com Kehl (2000), toma-se a expressão função fraterna para dar ênfase a dois pontos importantes nessa temática. Primeiramente, o uso da palavra "função" para expressar o caráter necessário, não contingente, da participação do semelhante no processo de tornar-se sujeito. O segundo ponto é considerar o termo "fraterna", com o intuito de resgatar, como enfoque de estudo e análise, a concepção de fratria. 
Desse modo, com base na perspectiva dos autores acima citados, constatase a importância da função fraterna na constituição do sujeito, entendendo o irmão como uma das primeiras representações do semelhante, que permite ao sujeito identificar-se, estruturar-se e reconhecer-se como ser social.

\section{A rivalidade, o companheirismo e a memória compartilhada na relação fraterna}

Analisando a literatura existente sobre a função fraterna, observa-se que a rivalidade fraterna é mais enfatizada do que o companheirismo. Entende-se a rivalidade como um sentimento legítimo que a criança desenvolve ao se deparar com alguém que irá fazê-la dividir o amor de seus pais. O Gênesis, livro da Bíblia (1962), registra que o primeiro crime de morte acontecido na Terra foi entre os irmãos Caim e Abel, por fatores muito próximos aos ciúmes e à rivalidade.

Mas, então, a rivalidade entre irmãos seria natural e universal? Pode-se dizer que sim. Embora possa ter mais intensidade entre os primogênitos ou entre irmãos do mesmo sexo, ou quando as idades são muito próximas, é fato que todos temos sentimentos de rivalidade. Afinal, todos experimentamos, nos primeiros meses de vida, a ideia ilusória de possuir inteiramente a figura materna. Constatar que outros têm direitos iguais e até mesmo maiores sobre ela instaura a relação de rivalidade (Viorst, 1988).

Segundo Klein (1974), todas as crianças sofrem fortes ciúmes dos irmãos. A autora enfatiza que as crianças menores que não têm conhecimento sobre geração e nascimento têm um conhecimento inconsciente que os bebês crescem no útero da mãe. Os ciúmes direcionariam um grande ódio e agressividade contra esse irmão ainda dentro do útero.

É importante enfatizar que, muitas vezes, "matamos" nossos irmãos e irmãs a cada dia, em nossa própria mente, por não aceitarmos dividir o amor de nossos pais. $\mathrm{O}$ ciúme seria a manifestação natural do sofrimento de ter de compartilhar o amor. Entretanto, com o tempo, percebemos que a perda do amor indivisível é necessária, pois também é compartilhada grande parte do amor que vivenciamos na sociedade. Assim, a relação entre irmãos seria um laboratório para expressão e compartilhamento desse sentimento legítimo que a vida nos impóe ao estarmos com um outro.

Além disso, outro aspecto positivo do ciúme, da rivalidade e da competição existentes entre irmãos é que esses sentimentos podem ser o motor do aprimoramento pessoal de cada um. $\mathrm{O}$ interesse de ser considerado "o 
melhor" pelos pais, de ser o objeto de amor dos mesmos impulsiona a criança a progredir, a ter um lugar de destaque na sociedade.

Kehl (2000) atribui a existência das grandes rivalidades fraternas, até a vida adulta, a um meticuloso trabalho por parte dos pais e educadores que se utilizam de métodos de "dividir para governar", estimulando entre os filhos a fantasia infantil de que só há lugar para um no amor parental. Essa poderia ser também a fantasia de um dos pais ou de ambos e não somente um método para o exercício do poder. Assim, a falta de lugar para a diversidade na família, o tipo de relação que os pais estimulam os filhos a estabelecerem, conscientemente ou não, trazem graves consequências tanto para o vencedor da disputa como para os supostos perdedores.

É importante focar também a cumplicidade, o companheirismo e solidariedade entre irmãos. A relação fraterna envolve uma interação longa entre os iguais, uma ampla rede de experiências durante a vida. "Eles não têm ideia do tamanho do impacto que causam uns nos outros. Impacto este que se dá através de mútua socialização, dos comportamentos de ajuda, das tarefas e atividades cooperativas, do simples companheirismo" (Silveira, 2002, p. 95).

$\mathrm{Na}$ relação pai-filho, há uma hierarquia pressuposta e determinada, a dominação do pai sobre o filho é imposta naturalmente. No vínculo fraterno, pode até haver uma dominação de um irmão sobre o outro, mas isso não é rígido e pode se inverter. Neste sentido, há maiores possibilidades de trocas, de partilhas das diferenças e semelhanças, de abertura entre os irmãos, facilitando suas relações.

Muitos filmes e contos infantis demonstram a cumplicidade entre os irmãos, ao se unirem para viver momentos desafiadores, após deixarem a casa dos pais. A história de João e Maria é representação de uma relação muito próxima entre irmãos, que caminham sozinhos num bosque cheio de bruxas. Em famílias em que o amor e a proteção por parte dos pais estão ausentes, pode ocorrer uma intensificação do laço fraterno. A unidade e a boa relação entre os irmãos possibilitam a eles se protegerem dos pais ou mesmo dos conflitos parentais.

Assim, numa relação conflituosa dos pais ou mesmo num momento de crise, a fratria também pode servir como base do equilíbrio familiar. Num período de crise familiar, como doença, divórcio, morte dos pais, dentre outros, a solidariedade entre os irmãos pode ser essencial para sustentação da família e equilíbrio psíquico de cada um. Diante desses acontecimentos, a fratria tende a uma vinculação maior, com o objetivo de restabelecer o sentimento de segurança e de força entre os irmãos. 
Entretanto, cabe enfatizar que a solidariedade entre os membros da fratria não se dá apenas diante de uma falha ou conflito parental. Pode haver uma relação de cumplicidade e bom entendimento, conforme, entre os irmãos, há respeito em relação às diferenças e partilha de seus segredos e experiências. Quando um irmão pode contar com o outro diante das situações da vida, cria-se entre eles uma relação de confidência e de proteção mútua.

Numa relação de cumplicidade, os membros da fratria poderão juntos aprender as coisas da vida, trocar e relembrar histórias familiares, elaborar a angústia e as perdas, desenvolver a criatividade por meio das brincadeiras, descobrir domínios desconhecidos, entre os quais a sexualidade (Goldsmid \& Carneiro, 2007).

É importante assinalar que o vínculo fraterno pode ser modificado e ressignificado ao longo da vida. Há uma construção longa e dinâmica dessa relação, com base nas trocas firmadas entre os irmãos.

A afetividade, a amizade, o bem-estar e o apego são características que podem estar presentes no relacionamento fraterno. O bem-estar está associado não apenas à rede de apoio social e emocional que um irmão pode proporcionar ao outro na vida adulta, mas principalmente à memória construída por eles de forma compartilhada. Tal construção proporciona ao sujeito um senso de identidade pessoal e familiar que adquire um significado cada vez mais crucial, conforme se caminha para estágios mais tardios da vida (Oliveira, 2005).

O sentimento de pertencimento à fratria é reforçado pela partilha de acontecimentos íntimos e de lembranças de momentos decisivos, o "banco de memórias" compartilhado entre eles. O acesso a esse "banco de memórias" possibilita aos irmãos um resgate da história de cada um, independente do tempo passado. A lembrança passa a ser a vida verdadeira, conforme é resgatada e repetida. "Acho que o que une os membros de uma fratria são as lembranças que eles partilharam, e, antes de mais nada, a memória dos objetos, aqueles que passam do mais velho ao segundo e do segundo ao terceiro" (Rufo, 2003, p. 246).

A memória compartilhada confere à fratria uma força e um poder incrível de retornar ao passado e ter acesso a referências históricas geralmente perdidas. $\mathrm{Na}$ fratria, alguns são melhor portadores das lembranças do que os outros. São, de certa forma, os fiadores de uma intimidade perdida, aqueles que guardaram e reproduziram as suas próprias lembranças e as de seus irmãos também. A qualidade das relaçôes fraternas se deve à possibilidade de reviverem juntos momentos poéticos, dramáticos ou engraçados partilhados no passado (Rufo, 2003). 
Geralmente os irmãos têm um conhecimento recíproco, consciente ou mesmo inconsciente, do funcionamento psíquico uns dos outros, por terem experimentado juntos sentimentos e conflitos ao longo do tempo na vida familiar. Logo, em cada irmão, perdurará uma "memória" dessas experiências familiares. Mesmo que, ao crescer, cada um dos irmãos siga um caminho diferente, a experiência da intimidade compartilhada deixará sua "marca" no inconsciente de cada um. $\mathrm{O}$ conhecimento da intimidade do outro irmão continuará sendo um legado e uma referência para a própria identidade (Goldsmid \& Carneiro, 2007).

Silveira (2002) faz um paralelo entre os irmãos que são considerados amigos e os amigos que são "irmãos de consideração". A autora diferencia a relação de amizade entre irmãos e a relação de amizade com os "irmãos de consideração", no sentido de a primeira ser imposta, não ter sido escolhida. No entanto, ela enfatiza que a possibilidade de o irmão ser um amigo é uma escolha.

No decorrer da vida, a maior proximidade e a troca entre os irmãos propicia um vínculo de amizade entre eles, mesmo que isso nem sempre ocorra. Logo, a escolha de ter um irmão como um amigo dependerá da forma como a relação se construiu, do espaço familiar oferecido, das semelhanças e das diferenças compartilhadas.

\section{Refletindo sobre o filme "Príncipe das marés"}

O "Príncipe das Marés" é um filme americano, de 1991, da categoria drama, dirigido por Bárbara Streisand, Nick Nolte e Jason Gould, com duração de 132 minutos. A família do filme é composta por Henry Wingo (pai), Lila (mãe) e os irmãos Luke, Tom e Savannah.

O pai era um pescador de camarôes, violento e agressivo, que vivia em conflito com a esposa, o que acarretava um clima de extrema ansiedade na família. A mãe, que priorizava seu bem-estar e sonhava em mudar de vida, era considerada pelos filhos, na infância, a mulher mais extraordinária do mundo. Luke era o irmão mais velho, visto como o mais corajoso por enfrentar o pai e sempre defender seus irmãos e sua mãe. Savannah e Tom eram os irmãos mais novos, gêmeos, que participavam mais "passivamente" da história familiar.

O filme se apresenta na fase adulta dos irmãos. Narra a história da vida de Tom, um professor de Inglês desempregado, em crise conjugal, que repentinamente precisa ir a Nova Iorque para cuidar de Savannah, que 
tentara novamente cometer suicídio e encontra-se num quadro de depressão severa.

Em Nova Iorque, Susan, a terapeuta de Savannah pede que Tom seja a "memória” da irmã para ajudá-la a prosseguir com o tratamento, uma vez que a comunicação com a paciente é muito difícil. Logo no começo, Tom admite ter tentado esquecer esses detalhes, mas se propóe a ajudar a irmã e a si próprio, iniciando uma viagem com Susan por recordações reprimidas e revivência de sua infância em família. Nesse processo de análise, Tom é levado a relembrar fatos traumáticos passados e a enfrentar os seus medos.

Assim, conforme episódios traumáticos são relembrados por Tom, é possível a reelaboração de vivências dolorosas e a compreensão do funcionamento familiar e dos contratos que foram sendo firmados na sua família. Durante o trabalho psicoterápico, chega-se a um momento em que o entendimento de Tom e o de Savannah se encontram: a lembrança do estupro sofrido por eles e pela mãe quando eram crianças, e que foi tratado como um segredo entre eles por toda vida. O segredo, a negação do acontecimento, foi a forma escolhida pela mãe para compartilhar o sofrimento.

Após a tentativa de suicídio, Savannah mencionou a palavra Callanwolde para a terapeuta, mas apenas repetiu a palavra sem desenvolver seu significado. Susan ainda perguntou a Tom se, para ele, havia algum sentido na palavra Callanwolde, mas ele negou ter conhecimento do que significava. No entanto, a abertura de Tom ao processo terapêutico revelou que a violência sexual sofrida por eles foi executada por fugitivos da prisão de Callanwolde. Tom chega a afirmar: "Acho que o silêncio era pior do que os estupros, três dias depois ela tentou se suicidar. Ela sabia ficar calada, mas não sabia mentir".

Tom já era a memória de Savannah, desde essa época, quando se lembrava de situações esquecidas e dava sentido às atitudes de sua irmã, que pareciam “sem lógica". Pode-se perceber, assim, a importância da memória construída e compartilhada com o irmão, conforme o resgate da história de um irmão viabiliza o acesso à memória do outro, pois ambos estão intimamente vinculados, tendo partilhado vivências comuns. Como ressalta Rufo (2003), o acesso ao "banco de memórias" compartilhado pelos irmãos possibilita a eles um resgate da história de cada um, independente do tempo passado. Para Oliveira (2005), a memória construída pelos irmãos de forma compartilhada proporciona a eles um senso de identidade pessoal e familiar que adquire um significado muito importante conforme 
o tempo passa.

É também importante ressaltar que, enquanto o segredo familiar é revelado, por meio da fala na terapia, Tom também começa a enxergar a possibilidade de repensar sua própria vida. Ele admite para a terapeuta que a vida toda tentara esquecer os detalhes esquecidos pela irmã, os traumas e lembranças tristes vividos em família. A depressão latente familiar havia deixado de ser segredo, pois não era mais possível negá-la e suportá-la, como havia ocorrido durante os últimos anos.

Assim, ao aceitar ser a memória de sua irmã Savannah, no trabalho psicoterápico, Tom pode resgatar a si mesmo, sua própria história que, automaticamente, está ligada à de sua irmã. $\mathrm{O}$ fato de a memória ser construída de forma compartilhada com o irmão traz ao sujeito um senso de identidade pessoal e familiar que tem uma grande significação para sua subjetividade. Dessa forma, Tom encontrou a possibilidade de se entender, reorganizar-se e, assim, poder amar, trabalhar e ver sua vida de outra maneira. Embora, para sua irmã, a consequência fora quase fatal, Tom demonstrou ter recursos internos de forma a responder, de modo mais saudável, aos conflitos familiares.

Tom, logo no início, conta que sua infância foi permeada pela relação conflituosa de seus pais e o clima de ansiedade e violência no ambiente familiar. Lembra que, diante disso, os irmãos desenvolveram entre si um ritual de mergulharem no rio, unindo-se como uma forma de fugir da realidade familiar. Nesse sentido, verificamos a forte ligação entre os irmãos, tentando diminuir a ansiedade da conflituosa relação entre os pais. O ritual é a representação da cumplicidade entre os irmãos, possibilitando a eles, juntos, elaborarem a angústia, lidarem com o conflito e até mesmo desenvolverem a criatividade por meio das brincadeiras. A presença do lúdico nessa fratria alivia o efeito da coação parental e se apresenta como possibilidade de compartilhar e suportar o conflito familiar.

A vivência do ritual também demonstra que existem experiências que só podem ser compartilhadas entre irmãos, entre os iguais. Por essa razão, um irmão exerce grande influência sobre o outro, modelando a história de cada um, com base nessas experiências e trocas vividas.

Além disso, é importante dizer que percebemos que a relação entre Luke, Tom e Savannah, na infância, era de companheirismo, amizade e compreensão. Isso se revela tanto na construção do ritual quanto em outros momentos do filme, como na cena em que Luke defende Tom da agressividade do pai. É importante dar destaque a esse tipo de relacionamento, pois o 
fortalecimento do vínculo fraterno, nessa fase, está relacionado à qualidade das relações que os irmãos serão capazes de estabelecer nas fases posteriores de suas vidas, não apenas entre si, mas com as outras pessoas.

O relacionamento de cumplicidade entre os irmãos Wingo se estendeu visivelmente à vida adulta. Ao falar de como enfrentou a morte de Luke, Tom explica que "parou, como um motor quebrado", "o irmão era um deus para ele" e seus problemas conjugais começaram logo após a perda do irmão. Savannah também demonstra que Luke representava apoio e amizade, reagindo à sua morte com mais uma tentativa de suicídio.

Além disso, Tom expressa claramente a relação de companheirismo com Savannah ao cuidar da irmã no hospital. Ele lia os livros escritos por Savannah, penteava seus cabelos; enfim, estava ali ao seu lado, mesmo sabendo que a irmã estava desacordada. Tom funcionou como rede de apoio social e emocional para a irmá num momento de dificuldade, demonstrando a importância que teve na sua recuperação e o apoio que pôde proporcionar na sua vida adulta.

Susan também questiona Tom quanto aos personagens do livro de Savannah, o pescador e o treinador, a quem ela se referia. Tom revela que ele era o treinador e Luke o pescador, e percebe que sua irmã escrevia sobre sua família. Ele começa a ler os livros da irmã e descobre que ela construiu um pseudônimo, o que é confirmado pela terapeuta: "No começo, Savannah dizia ser Renata Halpern. Dizia que seu pai era um peleteiro ${ }^{2}$ que sobreviveu ao holocausto. Logo percebi que não era judia, mas me fascinava ela dizer ser filha de sobreviventes. A que estava tentando sobreviver?”.

$\mathrm{Na}$ tentativa de encontrar um sentido para a revelação da terapeuta, Tom se lembra de acontecimentos importantes quanto à escrita de Savannah: "Minha mãe queimava o diário dela, achava desleal escrever sobre nossa horrível família. Após a queima do diário, Savannah escrevia com o dedo na areia, no ar".

Podemos supor que Savannah encontra em seu retorno ao trabalho de escrever poesias uma possibilidade de reestruturação de sua vida, um canal de comunicação com o mundo e, ao mesmo, tempo uma fonte de esperança e de vida. Assim, no final do filme, Savannah diz que escreverá um novo livro, que irá dedicá-lo a seu irmão, Tom Wingo, sua memória.

\section{Considerações finais}

2 Pessoa que prepara ou vende peles. O mesmo que peleiro. 
A função fraterna é um tema muito pouco presente nas pesquisas científicas. $\mathrm{Na}$ grande maioria, os autores que se interessaram por esse tema deram ênfase à relação de rivalidade e competição entre os irmãos. Propusemo-nos, então, a analisar também a questão do companheirismo e cumplicidade entre eles, enfatizando a importância da presença do irmão na construção da subjetividade e da memória compartilhada ao longo da vida. Tendo em vista que o filme "Príncipe das marés" retrata a história de irmãos consanguíneos que têm uma convivência, consideramos, neste trabalho, a concepção de laço fraterno como a ligação entre filhos do mesmo casal.

Os irmãos compartilham mais da vida um dos outros do que qualquer outra pessoa e têm fundamental importância na construção da subjetividade de cada um. A identificação das diferenças e semelhanças no irmão permite ao outro se perceber como sujeito. E, como pontua Lacan (1987), o ciúme infantil possibilita ao infante se reconhecer como sujeito e ser social. A família possibilita a primeira experiência de viver em grupo, e os irmãos permitem o desabrochar de sentimentos como ciúme e inveja, e também amor e carinho. $\mathrm{O}$ nascimento do irmão gera um turbilhão de sentimentos no sujeito, como ressaltado por Freud em "O pequeno Hans" (1909/1969) e em "História de uma neurose infantil" (1917/1969).

Obviamente, há uma influência e uma marca do legado parental na forma como a função fraterna vai se constituir. Os filhos representam o ideal comum de suas famílias e cultura. A fratria é, então, a portadora da psique das massas e do narcisismo parental. Ela terá a função de preencher, elaborar, reparar, restituir a deficiência no vínculo fraterno dos ancestrais, e suas vicissitudes serão marcadas pelo nível de diferenciação do vínculo, entre as gerações anteriores, e pela maneira com que ela pode se apropriar de sua história (Freud, 1921/1969).

Entretanto, a relação fraterna não é exclusivamente resultado do vínculo com os pais, mas tem vida própria. Ao longo da vida, o relacionamento fraterno pode sofrer contínuas transformações, havendo a possibilidade de cada irmão, de acordo com a história pessoal, valores e momento de vida, repensar a relação e dar novos significados aos irmãos em sua vida, inclusive alcançando novas formas de interação fraterna. Assim, existe a possibilidade de mudança e ressignificação da relação fraterna ao longo do tempo.

Assim, considera-se que o vínculo fraterno não é determinado com o nascimento do segundo filho, mas é uma relação construída na continuidade do tempo. A memória comum construída no decorrer da infância e da adolescência, a história compartilhada na família servirão como fatores 
essenciais para a manutenção, ou não, do vínculo fraterno na vida adulta.

Percebe-se, ainda, que o irmão representa a existência de um apoio potencial, mas também a possibilidade da preservação da unidade da família de origem. A figura fraterna permite ao sujeito remeter-se a si mesmo e à sua família de origem por meio da memória construída e compartilhada, a qual pode ser revisitada em qualquer momento ou fase da vida.

O filme "Príncipe das marés" retrata, especialmente, a importância do resgate da memória compartilhada para a subjetividade e para a saúde psíquica da irmã de Tom. O filme ainda demonstra que conforme Tom tenta resgatar a história de sua irmã, emergem lembranças e sentimentos de sua própria vida, ou seja, há a construção de uma memória compartilhada e um compartilhamento de uma memória, que é construída incessantemente.

A vida na fratria vai possibilitar, ainda, a cada um, experimentar a socialização antes de vivenciá-la. Como bem ressalta Oliveira (2005), a relação fraterna permite o aprendizado de um universo de habilidades e sentimentos, como a inveja, a cooperação, a disputa, o amor, a imitação e a admiração.

Assim, a fratria possibilita ao sujeito a oportunidade de aprender a viver uma relação igualitária com alguém diferente, suportando as diferenças e rivalidades. Desse modo, a fratria funciona como um verdadeiro laboratório e modelo para as relaçôes sociais estabelecidas fora do núcleo familiar.

\section{Referências}

Benghozi, P. \& Carneiro, T. F. (2001). Laço frátrio e continente frátrio como sustentação do laço genealógico. In T. F. Carneiro (org.). Casamento e família: do social à clínica. (pp. 112-118). Rio de Janeiro: Nau.

Bíblia. (1962). A Bíblia Sagrada contendo o Velho e o Novo Testamento. (João Ferreira de Almeida, trad.). Rio de Janeiro: Sociedade Bíblica do Brasil.

Freud, S. (1969). Análise de uma fobia em um menino de cinco anos. In S. Freud. Edição standard das obras completas de Sigmund Freud. (v. 10, pp. 13133). Rio de Janeiro: Imago. (Trabalho original publicado em 1909)

Freud, S. (1969). História de uma neurose infantil. In S. Freud. Edição 
standard das obras completas de Sigmund Freud. (v. 17, pp. 15-129). Rio de Janeiro: Imago. (Trabalho original publicado em 1917)

Freud, S. (1969). Psicologia das massas e análise do ego. In S. Freud. Edição standard das obras completas de Sigmund Freud. (v. 18, pp. 89-179). Rio de Janeiro: Imago. (Trabalho original publicado em 1921).

Freud, S. (1969). Totem e tabu. In S. Freud. Edição standard das obras completas de Sigmund Freud. (v. 13, pp. 15-129). Rio de Janeiro: Imago. (Trabalho original publicado em 1913).

Goldsmid, R. \& Carneiro, T. F. (2007). A função fraterna e as vicissitudes de ter e ser um(a) irmão(ã). Psicologia em Revista, 13 (2), 293-308.

Kaës, R. (1999). Complexo fraterno: aspectos de sua especificidade. In M. Ramos (org.). Casal e família como paciente. (2. ed., pp. 179-248). São Paulo: Escuta.

Kancyper, L. (1999). Confrontação de geraçôes: estudo psicanalítico. São Paulo: Casa do Psicólogo.

Kehl, M. R. (2000). Existe a função fraterna? In M. R. Kehl (org.). Função fraterna. (pp. 31-42). Rio de Janeiro: Relume Dumará.

Klein, M. (1974). Inveja e gratidão: um estudo das fontes do inconsciente. Rio de Janeiro: Imago.

Lacan, J. (1987). Os complexos familiares. Rio de Janeiro: Jorge Zahar.

Oliveira, A. (2005). Irmãos, meio-irmãos e coirmãos: a dinâmica das relaçôes fraternas no recasamento. Tese de Doutorado, Pontifícia Universidade Católica de São Paulo, Programa de Pós-graduação em Psicologia Clínica, São Paulo.

Rufo, M. (2003). Irmãos: como entender essa relação. Rio de Janeiro: Nova Fronteira.

Silveira, L. (2002). O relacionamento fraterno e suas características ao longo do ciclo vital da família. In A. Wagner (org.). Família em cena. (pp. 93-112). Petrópolis: Vozes.

Streisand, B. (Diretora) (1991). O príncipe das marés [fita de vídeo] [The prince of tides]. Estados Unidos: Columbia Pictures Corporation.

Viorst, J. (1988). Perdas necessárias. São Paulo: Melhoramentos. 